\title{
HUBUNGAN TINGKAT STRES DENGAN SIKLUS MENSTRUASI PADA MAHASISWI SEMESTER VIII DI STIKES WIRA MEDIKA BALI
}

\section{STRESS LEVEL CORRELATION TO CHANGE OF MENSTRUAL CYCLE IN THE SEMESTER VIII IN STIKES WIRA MEDIKA BALI}

\author{
Luh Made Wisniastuti ${ }^{1}$, Ns. A.A Sri Agung Adilatri, S.Kep², \\ Ika Setya Purwanti, SKM ${ }^{3}$ \\ STIKes Wira Medika Bali ${ }^{1}$ \\ RSUP Sanglah ${ }^{2}$ \\ STIKes Wira Medika Bali ${ }^{3}$
}

\begin{abstract}
ABSTRAK
Pendahuluan: Pada masa remaja terjadi suatu pertumbuhan dan perkembangan yang cepat dan disertai banyak perubahan baik secara psikis maupun fisik, termasuk di dalamnya ialah perkembangan organ-organ reproduksi atau organ seksual sehingga terjadinya kematangan yang ditunjukkan dengan adanya kemampuan melakukan fungsi reproduksi. Menstruasi atau haid adalah perubahan fisiologis dalam tubuh wanita yang terjadi secara berkala dan dipengaruhi oleh hormon reproduksi. Stres dapat menyebabkan terjadinya penekanan pada hormon dan dapat menyebabkan kegagalan ovulasi pada wanita. Penelitian ini bertujuan untuk mengetahui hubungan tingkat stres dengan siklus menstruasi pada mahasiswi semester VIII di STIKes Wira Medika Bali. Metode: Desain penelitian menggunakan pendekatan Cross Sectional. Sampel yang digunakan sebanyak 53 responden. Teknik pengambilan sampel dalam penelitian adalah Probability Sampling yaitu Simple Random Sampling. Data yang dikumpulkan menggunakan kuesioner tingkat stres dan kuesioner siklus menstruasi. Hasil: Hasil penelitian menunjukkan sebagian besar tingkat stres adalah sedang yaitu sebanyak 15 orang $(28,3 \%)$ dan siklus menstruasi responden sebagian besar adalah tidak teratur yaitu sebanyak 38 orang $(71,7 \%)$. Hasil analisis dengan menggunakan uji rank spearman menunjukkan bahwa terdapat hubungan yang signifikan antara tingkat stres dengan siklus menstruasi mahasiswi semester VIII dengan $p$ value 0,000 dengan koefisien korelasi 0,537 kekuatan hubungan sedang. Diskusi: Maka, mahasiswi diharapkan agar dapat menjaga kesehatan fisik dan mental.
\end{abstract}

Kata Kunci: tingkat stres, kepuasan, siklus menstruasi

\begin{abstract}
Introduction: In adolescence occurs a rapid growth and development and accompanied by many changes both psychically and physically, including in it is the development of reproductive organs or sexual organs so that the maturity indicated by the ability to perform reproductive function. Menstruation or menstruation is a physiological change in a woman's body that occurs periodically and is affected by reproductive hormones. Stress can cause stress on hormones and can cause ovulation failure in women. This study aims to determine the relationship of stress level with menstrual cycle at the semester VIII student in STIKes Wira Medika Bali Methods: The research design is using Cross Sectional approach. The
\end{abstract}


sample used is 53 respondents. Sampling technique in this research is Probability Sampling is Simple Random Sampling. Data were collected using a stress level questionnaire and a menstrual cycles questionnaire. Result: The result of this research shows that most of stress level is moderate that is 15 people $(28,3 \%)$ and menstruation cycle mostly irregular that is 38 people $(71,7 \%)$. The result of analysis by using spearman rank test showed that there was a significant correlation between stress level with menstrual cycle of female student of semester VIII with $p$ value 0,000 with correlation coefficient of 0.537 moderate relationship strength. Discussion: Thus, So, female students are expected to maintain physical and mental health.

Keywords: Stress level, Menstrual cycle

Alamat Korespondensi : Jl. Pantai Pererenan, Br.Pengembungan, Mengwi, Badung

Email

:Luhde_wisny@yahoo.com

\section{PENDAHULUAN}

Masa remaja merupakan periode peralihan dari masa anak ke masa dewasa (Sarlito, 2010). Menurut Badan Kependudukan dan Keluarga Berencana (BKKBN) rentang usia remaja adalah 10-24 tahun dan belum menikah (Menteri Kesehatan RI, 2014). Pada masa remaja inilah terjadi suatu pertumbuhan dan perkembangan yang cepat dan disertai banyak perubahan baik secara psikis maupun fisik, termasuk di dalamnya ialah perkembangan organ-organ reproduksi atau organ seksual sehingga terjadinya kematangan yang ditunjukkan dengan adanya kemampuan melakukan fungsi reproduksi.

Perkembangan pada tubuh remaja putri ditandai dengan payudara membesar, pinggul melebar, tumbuhnya rambut-rambut halus pada beberapa bagian tubuh serta kemampuan memproduksi sel telur (ovum), hal ini ditandai dengan terjadinya menstruasi. Menstruasi atau haid adalah perubahan fisiologis dalam tubuh wanita yang terjadi secara berkala dan dipengaruhi oleh hormon reproduksi. Wanita mengalami siklus menstruasi rata-rata terjadi sekitar 28 hari (Prayitno, 2014). Siklus menstruasi idealnya teratur setiap bulan dengan rentang waktu antara 24-35 hari setiap kali periode menstruasi (Haryono, 2016). Secara fisiologis siklus menstruasi normal menggambarkan kondisi organ reproduksi cenderung sehat dan tidak bermasalah. Sistem hormonal yang baik pada sistem reproduksi ditunjukkan dengan sel telur yang terus diproduksi serta siklus menstruasi yang teratur sehingga dengan siklus menstruasi yang normal, seseorang wanita akan lebih mudah mendapatkan kehamilan dan menghitung masa subur. Menstruasi pada wanita teratur setelah mencapai usia 18 tahun (Manuaba, 2009).

Perubahan siklus menstruasi dapat dipengaruhi oleh berbagai faktor seperti status gizi, berat badan, kelainan pada organ reproduksi, aktifitas yang berlebihan dan stres. Gangguan emosi atau stres merupakan penyebab tersering ketidakteraturan siklus menstruasi walaupun perubahan siklus menstruasi yang dialami tidak hanya pada saat wanita mengalami stres. Stres merupakan suatu reaksi fisik dan psikis terhadap setiap tuntutan yang menyebabkan ketegangan dan mengganggu stabilitas kehidupan sehari-hari (Priyanto, 2014). 
Stres sering kali membuat menstruasi tidak teratur. Hal ini terjadi karena stres sebagai rangsangan sistem saraf diteruskan ke susunan saraf pusat yaitu limbic system melalui transmisi saraf, selanjutnya melalui saraf autonomy akan diteruskan ke kelenjar-kelenjar hormonal hingga mengeluarkan cairan neurohormonal menuju hipofisis melalui sistem prontal guna mengeluarkan gonadotropin dalam bentuk FSH (Folikell Simulazing Hormone) dan LH (Leutenizing Hormone), yang disalurkan dari hipotalamus sehingga selanjutnya mempengaruhi proses menstruasi (Prawiroharjho, 2007).

Stres dapat menyebabkan terjadinya penekanan pada hormon dan dapat menyebabkan kegagalan ovulasi pada wanita. Stres pada remaja sama halnya dengan yang terjadi pada orang dewasa, stres bisa berefek negatif pada tubuh remaja. Reaksi mereka tersebut ditentukan oleh suasana dan kondisi kehidupan yang tengah mereka alami (Priyoto, 2014).

Penelitian Bieniasz J, et.al dalam Sianipar, et.al (2011) mendapatkan gangguan menstruasi di dunia yaitu sebanyak 5,3\% remaja mengalami amenorea primer, 18,4\% remaja mengalami amenorea sekunder, 50\% remaja mengalami oligomenorea, $10,5 \%$ remaja mengalami polimenorea, dan gangguan campuran sebanyak 15,8\%. Penelitian Siegberg, dkk (2007) mendapatkan sebanyak 63\% remaja di Indonesia mengalami menstruasi tidak teratur.

Dickinson (2013) memaparkan dalam penelitiannya bahwa stres meningkatkan resiko dari mahasiswa untuk mengalami berbagai gangguan mental dan penyakit fisik yang meliputi, kecemasan, depresi, sakit kepala, hilangnya energi dan gangguan tekanan darah. Stres yang dialami mahasiswa yang sedang mengerjakan tugas akhir umumnya bersifat negatif, sebab stres tersebut menimbulkan kerugiaan pada diri mahasiswa.

Bagi para mahasiswa tugas akhir merupakan tugas yang sangat berat. Pada umumnya perjalanan studi mahasiswa menjadi tersendat-sendat atau terhambat ketika menyusun tugas akhir. Mahasiswa pada awalnya memiliki semangat, motivasi dan minat yang tinggi terhadap tugas akhir namun keadaan itu menurun seiring dengan kesulitan-kesulitan yang dialami. Kesulitan itu membuat mahasiswa sering putus asa dan menyebabkan mahasiswa tidak dapat menyelesaikan studinya tepat waktu (Ningrum, 2011).

Suseno (2013) berpendapat bahwa dampak negatif stres individu terlihat secara fisik, emosi, intelektual, sosial dan spiritual. Stres fisik mengancam keseimbangan fisiologis, stres intelektual akan menggangu persepsi dan kemampuan menyelesaikan masalah, stres sosial akan menggangu hubungan individu satu dengan individu yang lain, sedangkan stres spiritual akan merubah pandangan individu terhadap kehidupan.

Pada penelitian Milanti (2017) yang meneliti tentang Gambaran FaktorFaktor Yang Mempengaruhi Siklus Menstruasi Pada Mahasiswa Fakultas Kedokteran Universitas Mulawarman didapatkan responden yang mengalami stres ringan mempunyai siklus menstruasi teratur sebesar $80 \%$ (12 orang). Pada stres berat sebesar $89,7 \%$ (35 orang) mengalami siklus tidak teratur dibanding siklus teratur hanya sebesar 10,3\% (4 orang). Penelitian yang dilakukan oleh Mesarini (2013) terhadap 35 responden di STIKES RS Baptis Kediri, didapatkan bahwa dari 35 mahasiswi yang diteliti menunjukkan keluhan perubahan siklus menstruasi terbesar yang diakibatkan oleh stres yaitu sebanyak 20 mahasiswi mengalami siklus 
menstruasi tidak teratur, dan sebanyak 15 mahasiswi mengalami siklus menstruasi teratur.

Penelitian dilakukan di STIKes Wira Medika Bali. Sekolah Tinggi Ilmu Kesehatan Wira Medika Bali merupakan salah satu institusi penyelenggaraan pendidikan kesehatan yang berdiri pada tanggal 30 November 2007 di Bali untuk penyelenggaraan Program Studi Ilmu Keperawatan jenjang program sarjana (S1) dan program Studi Analis Kesehatan jenjang Diploma (DIII). Mahasiswa S1 Keperawatan merupakan mahasiswa yang mengikuti perkuliahan di kelas dan pembelajaran praktik laboraturium dari semester awal sampai semester akhir. Pada mahasiswa semester akhir diwajibkan untuk mengikuti tugas akhir skripsi sebagai syarat untuk lulus dan memperoleh gelar sarjana.STIKes Wira Medika Bali khususnya pada mahasiswi semester VIII belum pernah dilakukan penelitian mengenai tingkat stres dengan siklus menstruasi, dan dari hasil studi pendahuluan yang telah dilakukan dengan metode wawancara singkat didapatkan data dari 30 mahasiswi Stikes Wira Medika angkatan delapan menyatakan sedang mengalami stres yang disebabkan oleh proses mengerjakan tugas akhir dengan keluhan mudah merasa letih, mudah marah, sulit untuk beristirahat, gelisah dan sulit tidur, dan merasa tidak percaya diri. Adapun kendala yang dialami mahasiswi semester delapan dalam mengerjakan tugas akhir diantaranya pencarian judul, mencari literatur yang sesuai dengan penelitian, keterbatasan waktu untuk mengerjakan proposal dan skripsi. Dari 30 mahasiswi yang diteliti, sebanyak 21 mahasiswi mengalami siklus menstruasi tidak teratur sedangkan sebanyak 9 mahasiswi mengalami siklus menstruasi teratur.

Berdasarkan uraian tersebut di atas, peneliti tertarik untuk melakukan penelitian dengan judul "Hubungan Tingkat Stres Dengan Siklus Menstruasi Pada Mahasiswi Semester VIII di Stikes Wira Medika Bali".

\section{BAHAN DAN METODE}

Desain yang digunakan penulis adalah deskriptif correlational dengan cross sectional. Penelitian deskriptif correlational yaitu metode penelitian yang dilakukan dengan tujuan utama untuk mengkaji hubungan antara variabel. Pendekatan dengan cross sectional adalah suatu penelitian yang mengambil data variabel independen dan dependen dinilai pada satu periode serta tidak ada tindak lanjut. Pada penelitian ini dilakukan untuk mengkaji hubungan tingkat stres dengan siklus menstruasi pada mahasiswi semester VIII di Stikes Wira Medika Bali yang diambil dalam satu kurun waktu.

Penelitian ini dilaksanakan di Sekolah Tinggi Ilmu Kesehatan Wira Medika Bali pada tanggal 4 April 2018.

Penelitian ini perlu dilakukan analisis terhadap data yang dikumpulkan dan mengetahui hubungan antar variabel yang ada. Data pada penelitian ini dikumpulkan dengan menggunakan kuesioner tingkat stres dan kuesioner siklus menstruasi. Besar sampel pada penelitian ini sejumlah 53 orang.

Teknik sampling pada penelitian ini ditetapkan secara probability sampling jenis “Simple Rondom Sampling” yaitu teknik penetapan sampel dilakukan secara acak tanpa memperhatikan strata yang ada dalam populasi (Nursalam, 2017). Analisis yang digunakan dalam penelitian ini adalah untuk mengetahui hubungan tingkat stres dengan siklus menstruasi pada mahasiswi semester VIII di Stikes Wira Medika Bali. Hasil pengukuran dalam penelitian ini adalah dengan skala ordinal 
dan nominal, sehingga untuk mengetahui hubungan tingkat stres dengan siklus menstruasi pada mahasiswi semester VIII di Stikes Wira Medika Bali dilakukan analisa dengan uji Rank Spearman dengan hasil sig 0,000.

\section{Karakteristik subjek penelitian}

\section{HASIL}

Subjek atau responden yang dijadikan sampel dalam penelitian ini adalah mahasiswi semester VIII di Stikes Wira Medika yang memenuhi kriteria inklusi. Sampel yang digunakan dalam penelitian ini yaitu 53 orang. Responden dalam penelitian ini dikarakteristikkan berdasarkan umur. Hasil identifikasi karakteristik responden dijabarkan sebagai berikut:

Tabel 1. Distribusi responden berdasarkan umur

\begin{tabular}{llcc}
\hline No & Umur & Frekuensi (f) & Persentase (\%) \\
\hline 1 & 21 th & 11 & 20,8 \\
2 & 22 th & 30 & 56,6 \\
3 & 23 th & 12 & 22,6 \\
\hline & Jumlah & 53 & 100 \\
\hline
\end{tabular}

Berdasarkan tabel diatas, dari 53 responden yang diteliti karakteristik responden terbanyak berumur 22 tahun yaitu 30 orang $(56,6 \%)$. penelitian

Hasil pengamatan terhadap obyek penelitian berdasarkan variabel Tabel 2. Tingkat Stres Mahasiswi Semester VIII di STIKes Wira Medika Bali

\begin{tabular}{llcc}
\hline No & Tingkat & Frekuensi (f) & Persentase (\%) \\
& Stres & & \\
\hline 1 & Normal & 8 & 15,1 \\
2 & Ringan & 10 & 18,9 \\
3 & Sedang & 15 & 28,3 \\
4 & Berat & 8 & 15,1 \\
5 & Sangat Berat & 12 & 22,6 \\
& & & \\
\hline & Jumlah & 53 & 100 \\
\hline
\end{tabular}

Berdasarkan tabel diatas, dari 53 responden menunjukkan bahwa tingkat stres yang tertinggi yaitu stres sedang sebanyak 15 orang $(28,3 \%)$.

Tabel 3. Hasil Pengukuran Siklus Menstruasi Mahasiswi Semester VIII di Stikes Wira Medika Bali

\begin{tabular}{llcc}
\hline No & Siklus Menstruasi & Frekuensi (f) & Persentase (\%) \\
\hline 1 & Teratur & 15 & 28,3 \\
2 & Tidak Teratur & 38 & 71,7 \\
& & & \\
\hline & Jumlah & 53 & 100 \\
\hline
\end{tabular}


Berdasarkan tabel diatas, menunjukkan dari 53 responden sebanyak 38 orang $(71,7 \%)$ mengalami siklus menstruasi yang tidak teratur.

\section{Hasil Analisis Data}

Tabel 4. Hasil Analisis Hubungan Tingkat Stres Dengan Siklus Menstruasi Pada Mahasiswi semester VIII d Stikes Wira Medika Bali

\begin{tabular}{|c|c|c|c|c|c|}
\hline \multirow[b]{2}{*}{ Tingkat Stres } & \multicolumn{2}{|c|}{ Siklus Menstruasi } & \multirow[b]{2}{*}{ Total } & \multirow[b]{2}{*}{$\mathrm{r}$} & \multirow[b]{2}{*}{$\mathrm{p}$} \\
\hline & Teratur & Tidak Teratur & & & \\
\hline Normal & 8 & 0 & 8 & & \\
\hline $\mathrm{F}$ & $(15,1 \%)$ & $(0,0 \%)$ & $(15,1 \%)$ & & \\
\hline \multicolumn{6}{|l|}{$\%$} \\
\hline Ringan & 3 & 7 & 10 & & \\
\hline $\mathrm{F}$ & $(5,7 \%)$ & $(13,2 \%)$ & $(18,9 \%)$ & & \\
\hline \multicolumn{6}{|l|}{$\%$} \\
\hline Sedang & 2 & 13 & 15 & & \\
\hline $\mathrm{F}$ & $(3,8 \%)$ & $(24,5 \%)$ & $(28,3 \%)$ & 0,537 & 0,000 \\
\hline \multicolumn{6}{|l|}{$\%$} \\
\hline Berat & 1 & 7 & 8 & & \\
\hline $\mathrm{F}$ & $(1,9 \%)$ & $(13,2 \%)$ & $(15,1 \%)$ & & \\
\hline \multicolumn{6}{|l|}{$\%$} \\
\hline $\begin{array}{l}\text { Sangat Berat } \\
\mathrm{F}\end{array}$ & $\begin{array}{c}1 \\
(1,9 \%)\end{array}$ & $\begin{array}{c}11 \\
(20,8 \%)\end{array}$ & $\begin{array}{c}12 \\
(22,6 \%)\end{array}$ & & \\
\hline \multicolumn{6}{|l|}{$\%$} \\
\hline Total & $\begin{array}{c}15 \\
(28,3 \%)\end{array}$ & $\begin{array}{c}38 \\
(71,7 \%)\end{array}$ & $\begin{array}{c}53 \\
(100 \%)\end{array}$ & & \\
\hline$\%$ & & & & & \\
\hline
\end{tabular}

Berdasarkan hasil uji statistik Rank Spearman didapatkan nilai signifikan yaitu 0,000 dengan nilai $p<0,05$ yang berarti Ho ditolak dan Ha diterima yang artinya terdapat hubungan yang signifikan antara tingkat stres dengan siklus menstruasi. Hasil menunjukkan bahwa koefisien korelasi sedang yaitu 0,537 dengan arah hubungan searah.

\section{PEMBAHASAN}

Rasmun (2005) faktor-faktor yang mempengaruhi seseorang yang mengalami stres seperti kehilangan, konflik keluarga, masalah prestasi atau kegagalan, kemampuan seorang individu dalam mempersepsikan stres, rendahnya intensitas terhadap stimulus, dan pengalaman masa lalu. Oleh karena itu dampak yang terjadi pada seseorang yang mengalami stres dapat terjadi produksi keringat meningkat, aktivitas metabolik meningkat, ketegangan otot meningkat, selain itu menurut teori Priyoto (2014) menyebutkan bahwa dampak yang ditimbulkan saat stres adalah sakit kepala yang berlebihan, tidur menjadi tidak nyenyak, gangguan pencernaan, hilangnya nafsu makan, produksi keringat yang berlebihan di seluruh 
tubuh, menurunnya daya ingat, mudah lupa dengan suatu hal, mudah marah, kecemasan yang berlebihan terhadap segala sesuatu, merasa sedih dan depresi.

Secara teoritis, stres sebagai ketidakmampuan mengatasi ancaman yang dihadapi oleh mental, fisik, emosional dan spiritual manusia tersebut. Tingkat stres adalah tahapan gejala-gejala stres yang ada pada diri seseorang yang seringkali tidak disadari. Hal ini bisa disebabkan karena faktor internal dan eksternal. Faktor internal bisa disebabkan karena kesehatan atau penyakit yang dialami, karena tingkat kesehatan yang ada pada seseorang akan mempengaruhi stres yang dialami, selain itu stres dapat disebabkan karena kelebihan beban dan kebosanan dengan proses pembelajaran yang berlangsung. Apabila seseorang berada dalam kondisi ini, maka seseorang tersebut akan mengalami perasaan resah, gelisah, cemas, hingga frustasi berat atau putus asa. Dalam keadaan stres, sel-sel radikal bebas yang sebelumnya tidak berkembang kini berkembang biak dengan cepat (Mumpuni, 2010). Menurut Kusmiran (2011) mengatakan bahwa stres dapat menyebabkan perubahan pada sistemik tubuh. Khususnya sistem pernapasan dalam hipotalamus melalui perubahan prolaktin atau endogen opiat yang dapat mempengaruhi elevasi kortisol dan menurunkan hormone lutein (LH) yang menyebabkan gangguan pada siklus menstruasi.

Hasil analisa dari 53 responden yang diteliti menunjukkan bahwa terdapat 8 orang $(15,1 \%)$ mengalami stres normal, 10 orang $(18,9 \%)$ mengalami stres ringan, 15 orang $(28,3 \%)$ mengalami stres sedang, 8 orang $(15,1 \%)$ mengalami stres berat, dan sebanyak 12 orang $(22,6)$ mengalami stres sangat berat.

Hal ini sejalan dengan penelitian Pathmanathan (2013) mengenai stres pada mahasiswa semester VIII yang menyusun skripsi yang dilakukan di Universitas Sumatra Utara pada Fakultas Kedokteran. Hasil penelitian menunjukkan dari 100 responden sebanyak 35 orang (35\%) mengalami stres ringan 61 orang $(61 \%)$ mengalami stres sedang dan 4 orang (4\%) mengalami stres berat. Hal ini juga sejalan dengan penelitian Milanti (2017) mengenai gambaran faktor-faktor yang mempengaruhi menstruasi pada mahasiswi Fakultas Kedokteran. Hasil penelitian menunjukkan dari 194 responden sebanyak 15 orang $(7,7 \%)$ mengalami stress ringan, 140 orang $(72,2 \%)$ mengalami stres sedang, dan sebanyak $39(20,1 \%)$ mengalami stres berat.

Berdasarkan uraian di atas peneliti dapat menggaris bawahi, stres yang terjadi pada mahasiswi pada masa perkuliahan disebabkan karena adanya permasalahan akademik maupun non akademik. Stres yang terjadi pada mahasiswi dapat menyebabkan terjadinya perubahan perilaku pada mahasiswi seperti penurunan energi cenderung mengekspresikan pandangan pada orang lain, perasaan marah, kecewa, frustasi, bingung, putus asa, serta melemahkan tanggung jawab.

Secara teoritis, menstruasi adalah peluruhan lapisan - lapisan spons endometrium dengan perdarahan yang berasal dari pembuluh darah yang robek (Strigh, 2009). Siklus menstruasi biasanya adalah 28 hari, tetapi siklus juga bisa mencapai 35 hari atau bahkan lebih pendek yaitu 24 hari. Jumlah ini dihitung dari hari pertama menstruasi sampai hari terakhir menjelang menstruasi berikutnya (Prayitno, 2014).

Biasanya menstruasi rata-rata terjadi 5 hari, kadang-kadang menstruasi juga dapat terjadi sekitar 2 hari sampai 7 hari. Faktor-faktor yang mempengaruhi perubahan siklus menstruasi yaitu gangguan hormon, stres, obesitas, serta olahraga 
yang berlebihan. Gangguan tersebut menyebabkan hormon yang berperan dalam siklus menstruasi akan terganggu, hormon tersebut adalah FSH, LH, estrogen dan progesteron. Jika terjadi gangguan pada hormon FSH dan LH maka sel telur tidak akan terbentuk, jika demikian maka hormon estrogen dan progesteron juga tidak akan terbentuk sebagaimana mestinya. Siklus menstruasi juga akan terganggu. Estrogen merupakan hormon yang mempengaruhi rangkaian siklus menstruasi. Dampak jika gangguan siklus menstruasi yang tidak ditangani dengan benar akan mengakibatkan gangguan kesuburan (Prawirohardjo, 2006).

Berdasarkan hasil penelitian yang dilakukan pada 53 responden, menunjukkan sebanyak 15 orang $(28,3 \%)$ mengalami siklus menstruasi teratur dan 38 orang $(71,7 \%)$ mengalami siklus menstruasi yang tidak teratur. Hal ini sejalan dengan penelitian Mesarini (2013) mengenai stres dan mekanisme koping terhadap gangguan menstruasi pada remaja putri, hasil menunjukkan terhadap 35 responden didapatkan bahwa 20 mahasiswi mengalami siklus menstruasi tidak teratur dan 15 mahasiswi mengalami siklus menstruasi teratur.

Berdasarkan uraian di atas peneliti dapat menekankan bahwa, terjadinya ketidakteraturan siklus menstruasi disebabkan karena adanya beban psikis yang terjadi pada setiap wanita, dimana beban tersebut dapat menyebabkan terjadinya perubahan iskemik dalam tubuh, yang dapat mempengaruhi hormon LH pada tubuh.

Berdasarkan hasil analisa hubungan tingkat stres dengan siklus menstruasi pada mahasiswi semester VIII di Stikes Wira Medika Bali, sebanyak 53 responden yang dikumpulkan dengan menggunakan metode Cross Sectional dengan teknik pengambilan sampel Simple Random Sampling dengan melakukan penyebaran kuesioner serta menggunkan uji Rank Sperman didapatkan angka p value sebesar $0,000<$ tingkat signifikansi yang ditentukan yaitu 0,05 . Hasil ini menunjukkan ada hubungan yang bermakna antara tingkat stress dengan siklus menstruasi pada mahasiswi semester VIII di Stikes Wira Medika Bali. Hasil uji Rank Sperman didapatkan nilai koefisien korelasi 0,537 yang dapat diartikan bahwa tingkat stres dengan siklus menstruasi memiliki tingkat hubungan yang sedang, serta arah hubungan yang positif dimana semakin tinggi tingkat stres maka semakin besar kemungkinan responden akan mengalami gangguan siklus menstruasi.

Hal ini sesuai dengan teori yang menyebutkan bahwa stres sering kali membuat siklus menstruasi tidak teratur. Stres pada seseorang akan memicu pelepasan hormon kortisol dalam tubuh seseorang, dimana hormon kortisol ini akan bekerja mengatur seluruh sistem didalam tubuh, dalam menghadapi stres yang ada. Biasanya hormon kortisol ini dijadikan tolak ukur untuk melihat derajat stres seseorang. Ini disebabkan karena stres yang dialami mempengaruhi kerja hormon kortisol yang diatur oleh hipotalamus otak dan kelenjar pituitari (Yustinus, 2009). Dengan dimulainya aktifitas hipotalamus ini, hipofisis mengeluarkan FSH dan proses stimulasi ovarium akan menghasilkan estrogen. Jika terjadi gangguan pada hormon FSH dan LH maka menyebabkan tidak terbentuknya sel telur. Jika demikian, hormon estrogen juga tidak terbentuk sebagaimana mestinya dan hormon estrogen juga mempengaruhi rangkaian siklus menstruasi (Carole, 2009).

Berdasarkan uraian di atas peneliti berasumsi bahwa ada hubungan antara stres dengan siklus menstruasi pada mahasiswi angkatan VIII di STIKes Wira Medika Bali dimana dalam hal ini tingkat stres yang tinggi pada mahasiswi semester akhir kemungkinan karena banyaknya tugas yang harus diselesaikan dan kurangnya 
kemampuan manajemen waktu sehingga hal tersebut dapat menjadi faktor pencetus stres. Dapat disimpulkan semakin tinggi tingkat stres responden maka semakin besar kemungkinan responden akan mengalami gangguan siklus menstruasi.

\section{SIMPULAN DAN SARAN}

Berdasarkan hasil penelitian yang dilakukan Stikes Wira Medika menunjukkan bahwa tingkat stres dalam kategori sedang sebanyak 15 orang responden $(28,3 \%)$, siklus menstruasi sebanyak 38 orang $(71,7 \%)$ responden mengalami siklus menstruasi tidak teratur, serta ada hubungan yang signifikan antara tingkat stres dengan siklus menstruasi pada mahasiswi semester VIII di Stikes Wira Medika Bali dengan $\mathrm{p}$ value $\mathrm{p}$ value sebesar $0,000<0,05$, dan nilai koefisien korelasi 0,537 dengan tingkat hubungan sedang, serta arah hubungan yang positif dimana dimana semakin tinggi tingkat stres maka semakin besar kemungkinan responden akan mengalami gangguan siklus menstruasi.

\section{SARAN}

Berdasarkan hasil penelitian dan pembahasan diatas dapat disampaikan saran sebagai berikut :

Bagi institusi pendidikan STIKes Wira Medika Bali hasil penelitian ini diharapkan dapat memberikan informasi mengenai hubungan tingkat stres dengan siklus menstruasi, sehingga penelitian ini bisa menjadi acuan khusus bagi institusi untuk menanggulangi permasalahan yang dihadapi saat mengerjakan tugas akhir skripsi.

Kepada Mahasiswi Stikes Wira Medika hasil penelitian ini diharapkan kepada siswi agar dapat menjaga kesehatan fisik dan mental, meningkatkan keyakinan atau pandangan yang lebih positif, berusaha untuk melakukan keterampilan memecahkan masalah yang lebih baik sehingga stres yang terjadi dapat dikurangi agar tidak menjadi stres yang berat dan siklus menstruasi kembali normal.

Kepada Peneliti Selanjutnya hasil penelitian ini diharapkan dapat dijadikan bahan kajian untuk penelitian lebih lanjut kedepannya. Dengan mempertimbangkan keterbatasan peneliti ini, yaitu mengidentifikasi faktor lain yang mempengaruhi gangguan siklus menstruasi seperti faktor gizi, obesitas dan aktifitas fisik, dan menggunakan metode penelitian dengan teknik wawancara. Penelitian ini dapat dijadikan reverensi bagi peneliti selanjutnya serta mampu dikembangkan sehingga hasil lebih baik.

\section{DAFTAR PUSTAKA}

Carole. 2009. Menstruas. Jakarta : Salemba Medika Haryono. 2016. Siap Menghadapi Menstruasi \& Menopause. Yogyakarta Irianto. 2014. Biologi Reproduksi. Bandung. ALFABETA . 2015. Kesehatan Reproduksi. Bandung. ALFABETA

Kusmiwan, Eny. 2011. Kesehatan Reproduksi Remaja dan Wanita. Jakarta : Selemba Medika 
Kusmiran, E. 2011. Menarche. Yogyakarta: Muha Medika

Mashudi, F. 2012. Psikologi Konseling. Jogjakarta. IRCiSoD

Mumpuni, W. 2010. Cara Jitu Mengatasi Stres. Yogyakarta : ANDI

Milanti, Indah. 2017. Gambaran Faktor-Faktor Yang Mempengaruhi Siklus Menstruasi Pada Mahasiswi Fakultas Kedokteran Universitas Mulawarman. Jurnal Kebidanan Mutiara Mahakam: Volume 5, Nomor 1

Monica. 2015. Hubungan Tingkat Aktivitas Fisik Dengan Dysmenorrhea Primer Pada Remaja Umur 13-15 Tahun Di Smp. K. Harapan Denpasar. Denpasar: Skipsi. Universitas Udayana

Notoatmodjo, S. 2005. Metodologi Penelitian Kesehatan. Jakarta : Rineka Cipta

Nursalam. 2013. Metodologi Penelitian Ilmu Keperawatan: Pendekatan Praktis Edisi 3. Jakarta : Salemba Medika 2017. Metodologi Penelitian Ilmu Keperawatan: Pendekatan Praktis Edisi 4. Jakarta : Salemba Medika

Potter, P.A \&Perry, A.G. 2005. Fundamental Keperawatan: Konsep, Proses, dan Praktik Edisi 4. Jakarta : EGC

Proverawati, A dan Misaroh, S. 2009. Menarche, Menstruasi Pertama Penuh Makna. Yogyakarta : Nuha Medika

Prawirohardjo, S. 2007. Ilmu Kandungan Edisi 2. Jakarta : EGC

Prayitno. 2014. Kesehatan Organ Reproduksi Wanita. Yogyakarta : Saufa

Priyoto. 2014. Konsep Manajemen Stres. Yogyakarta : Nuha Medika

Purwoastuti, dkk. 2015. Panduan Materi Kesehatan Reproduksi dan Keluarga Berencana. Yogyakarta. Pustaka Baru Press

Rasmun. 2005. Stres, Koping dan Adaptasi Teori dan Pohon Masalah Keperawatan. Jakarta : CV Sagung Seto

Risky, Novia. 2015. Gizi Dengan Siklus Menstruasi Pada Remaja Putri. Fakultas Keperawatan Hubungan status Aisyiyah Yogyakarta: Skripsi. Universitas Aisyiyah Yogyakarta

Riwidikdo. 2007. Metodelogi Penelitian Kesehatan. Jakarta: Bina Pustaka.

Sunaryo. 2004. Psikologi Untuk Keperawatan. Jakarta : EGC

Sugma, E.S. 2015. Pengaruh Stres Terhadap Siklus Menstruasi Pada Remaja. Fakultas Kedokteran Universitas Lampung: Jurnal Majority: Volume 4, Nomor 1

Susanti. 2015. Faktor-faktor Yang Berhubungan Dengan Gangguan Siklus Menstruasi Pada Wanita Usia Subur. Stikes Prima Nusantara Bukittinggi. Jurnal : Volume 6, Nomor 2

Suseno, Ageng. (2013). Kecenderungan Perilaku Agresif Ditinjau Dari Stres Akademik Pada Siswa SMA Negeri 1 Pemalang. Jurnal Psikologis: Volume 2, Nomor 3

Stright, Barbara R. 2009. Panduan Belajar Keperawatan Ibu dan Bayi Baru Lahir. Jakarta : EGC

Wangsa, T. 2009. Menghadapi Stres dan Depresi. Yogyakarta: Tugu

Yustinus. 2009. Siklus Menstruasi Pada Wanita. Jakarta : EGC 